\title{
Android Educational Game for Criminology Students
}

DOI: https://doi.org/10.47175/rissj.v3i1.358

\section{| Guiamarudin S. Daud |}

\author{
Mindanao State \\ University-Maguindanao, \\ Philippines \\ guiamsdaud@msumaguind \\ anao.edu.ph
}

\begin{abstract}
The researcher developed an app for Criminology students; the focus of this project is to provide them with a mobile educational game that could help them boost their mental awareness on topics and knowledge in the field of criminology. Target users are criminology students. Moreover, the user of this game will be addressed by the proponent to develop this system. Thus, it develops an android game application dedicated to criminology students. Promote criminology students' knowledge and awareness in a more intuitive and enjoyable way and create and establish a 100\% functional android-based application. The programming language used was JAVA, which is specialized in mobile game development. The integrated development environment (IDE) used was Eclipse JUNO, a standalone programming environment that is suitable for the coding structure and interface design of the developed system. A graphic editing tool was also utilized to further enhance the objects used in the game. The finished app was tested using the android tablet model Cloud pad 701 TV having Android 4.2.2 version firmware. The Codified Project Management Framework was then used in the development of the project. Based on the result of the Interface of the system obtained, the Android App concept for criminology students is effective and excellent. It was further recommended that the developed app still be reviewed thoroughly in terms of its data content validity. It was also recommended that the system will be developed further for more additional features. KEYWORDS

Android Educational Game; criminology; Mobile Educational game
\end{abstract}

\section{INTRODUCTION}

As technology progresses, computers have also improved. Tablets, touchpads, and mini pads are in demand nowadays. Most of these tablets are powered by the Android OS system. Through the years several versions of the operating system have been developed, which are now used to execute tablets, smartphones, and android phones.

Android is the most popular mobile platform in the world. Android development is becoming an increasingly popular field. For developers who want to target a huge, diverse audience, the in-demand use of a computer system software has been implemented from PC, mobile and even other means of technology. Even Applications / Games are now invading it. In years, Games are also being implemented using the World Wide Web. Programmers and developers continuously discover and develop new faces and styles of games or apps (www.study.com).

In line with this, several android applications are being developed to run the tablets. Most are for gaming, application system, knowledge-based system, and data processing. Android tablets, smartphones, and touchpads are in demand in today's generation. People are purchasing these gadgets not just for personal and business purposes, but also to lessen the 
boredom and stress from work and daily life. One way is by engaging in game applications. Games are one of the attractive features that android tablets, smartphones, and touchpads have. The different versions, styles, gameplays, and storylines make the common user curious to explore and enjoy the game. From the famous Facebook game CANDY Crush, tablet games like Plants versus Zombies, Temple run, Bubble Mania, and Angry Birds, people get to explore and download games that might fit with their needs to lessen the boredom or even assist them in learning.

The researcher would like to develop an app for Criminology students; the focus of this project is to provide them with a mobile educational game that could help them boost their mental awareness on topics and knowledge in the field of criminology. Moreover, the game will be called Criminology Android Educational Game.

Computer games are addicting and divert students' attention from their studies. Because of this situation, it may cause negative effects that can affect their academic performance in school. Thus, the researcher decided to create a mobile educational game for android phones that will enhance the learning ability of the students, and at the same time, allow them to entertain themselves. Target users are criminology students. Moreover, the user of this game will be addressed by the proponent to develop this system. Thus, it develops an android game application dedicated to criminology students. Promote criminology students' knowledge and awareness in a more intuitive and enjoyable way and create and establish a $100 \%$ functional android-based application.

\section{RESEARCH METHODS}

The programming language used was JAVA, which is specialized in mobile game development. The integrated development environment (IDE) used was Eclipse JUNO, a stand-alone programming environment that is suitable for the coding structure and interface design of the developed system. A graphic editing tool was also utilized to further enhance the objects used in the game. The finished app was tested using the android tablet model Cloud pad 701 TV having Android 4.2.2 version firmware. The Codified Project Management Framework was then used in the development of the project.

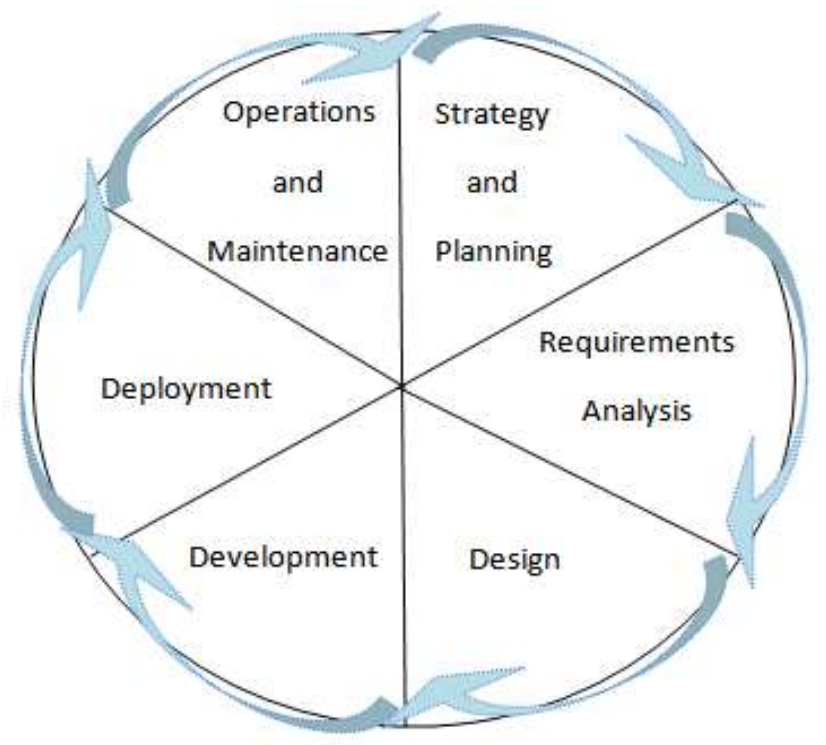

Figure 1. Codified Project Management Framework 


\section{Strategy and Planning}

In this phase, the researcher had analyzed what data is needed to be used in the development of the proposed system. Literature was gathered to determine if the system to be developed will be of great help to the students that serve to be the primary end-user of the app. The researcher conducted internet research and consulted some experts in criminology to ask for some information about the system that was developed. Some literature was also consulted in the books and e-books. Designs were even based on other android games that are conducive to developing the system. The researcher had also visited the library to conduct detailed research and read literature that is relevant to the study. The best-printed materials are chosen from that gathered information that would best serve in helping the researcher in developing the game.

\section{Requirements Analysis}

Software requirement was determined during this phase. In this phase, the researcher had selected the most suitable IDE to be used in designing and coding the game. Thereafter, related pictures that will be commensurate with the possible answers on each question were trimmed down and some parts were omitted since the concept of the game was guessing a picture through the missing part of it.

\section{Design and Development}

The Criminology Android Educational Game was coded and designed using JUNO Eclipse. In this phase, it described how designs are translated into code, which will include the information where the algorithm will be coded and tested. In this phase, a programming tool like the eclipse programming language integrated with ADT (Android Developer Tools), a plugin for Eclipse that provides a suite of tools was used. This tool offers access to many features that will help develop Android applications (www.study.com). ADT provides GUI access to many of the command line SDK Tools as well as a UI design tool for prototyping, designing, and building the application's user interface. See the figures below.

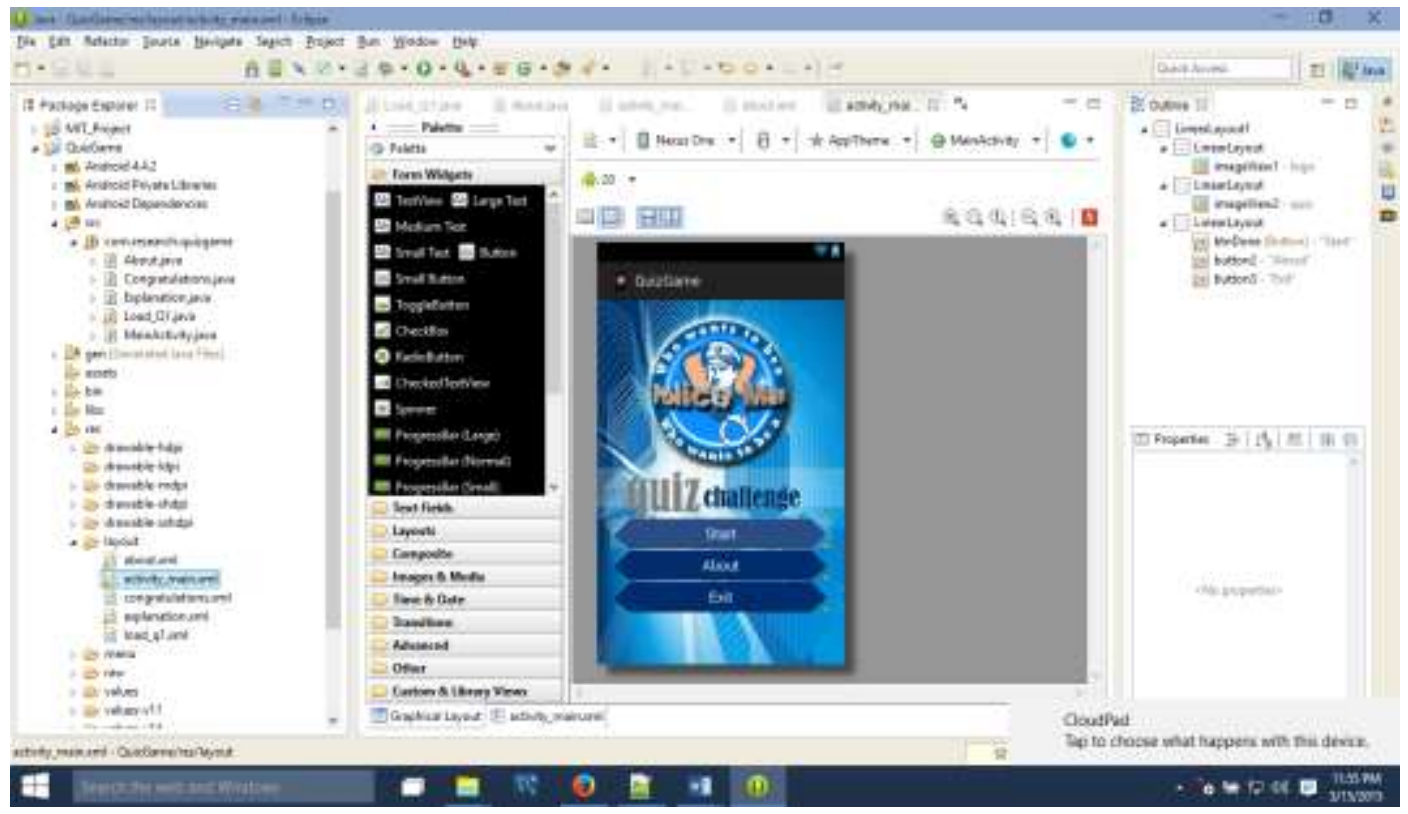

Figure 2. The designing of the Main Screen menu of the app. 


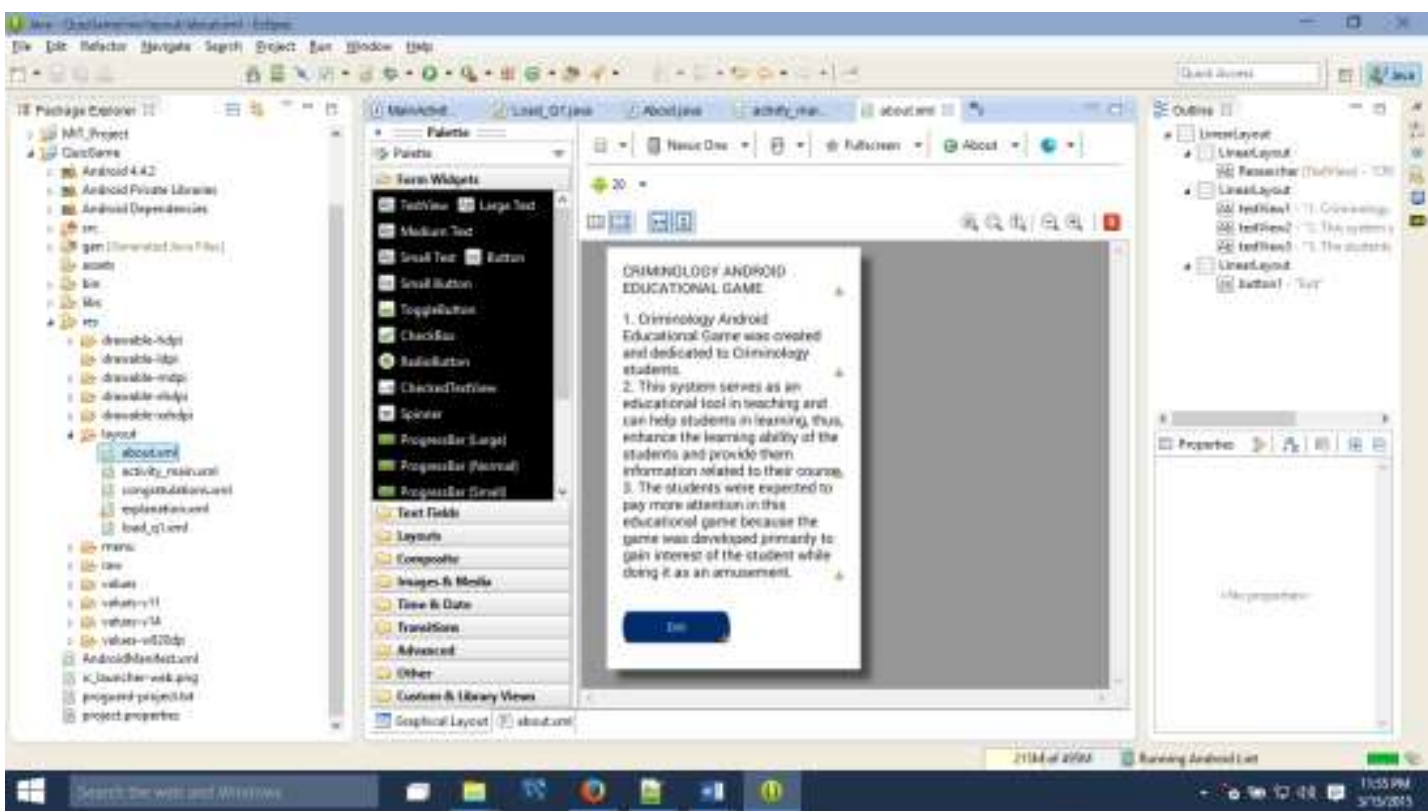

Figure 3. Designing the About The Program screen form.

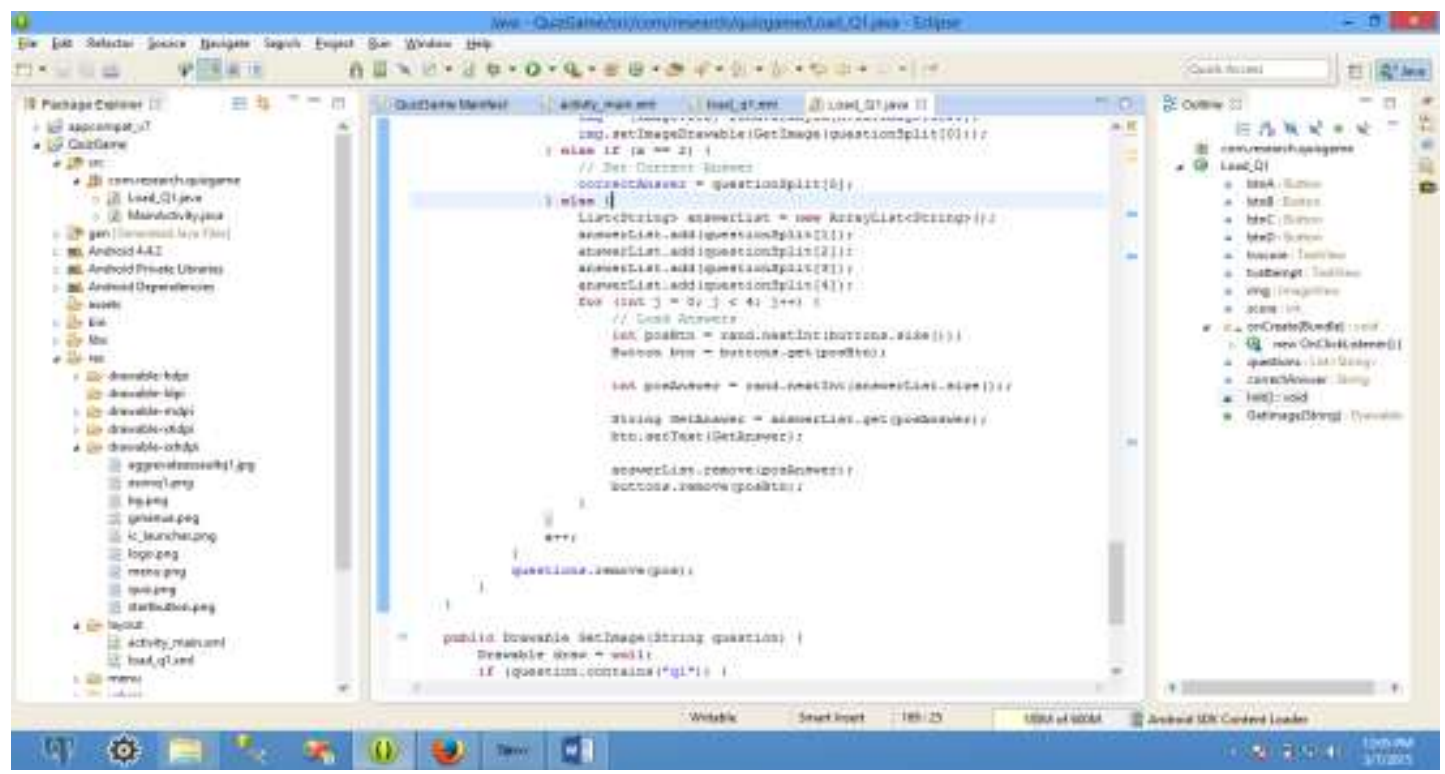

Figure 4. The image showing the coding screen of the developed game. 


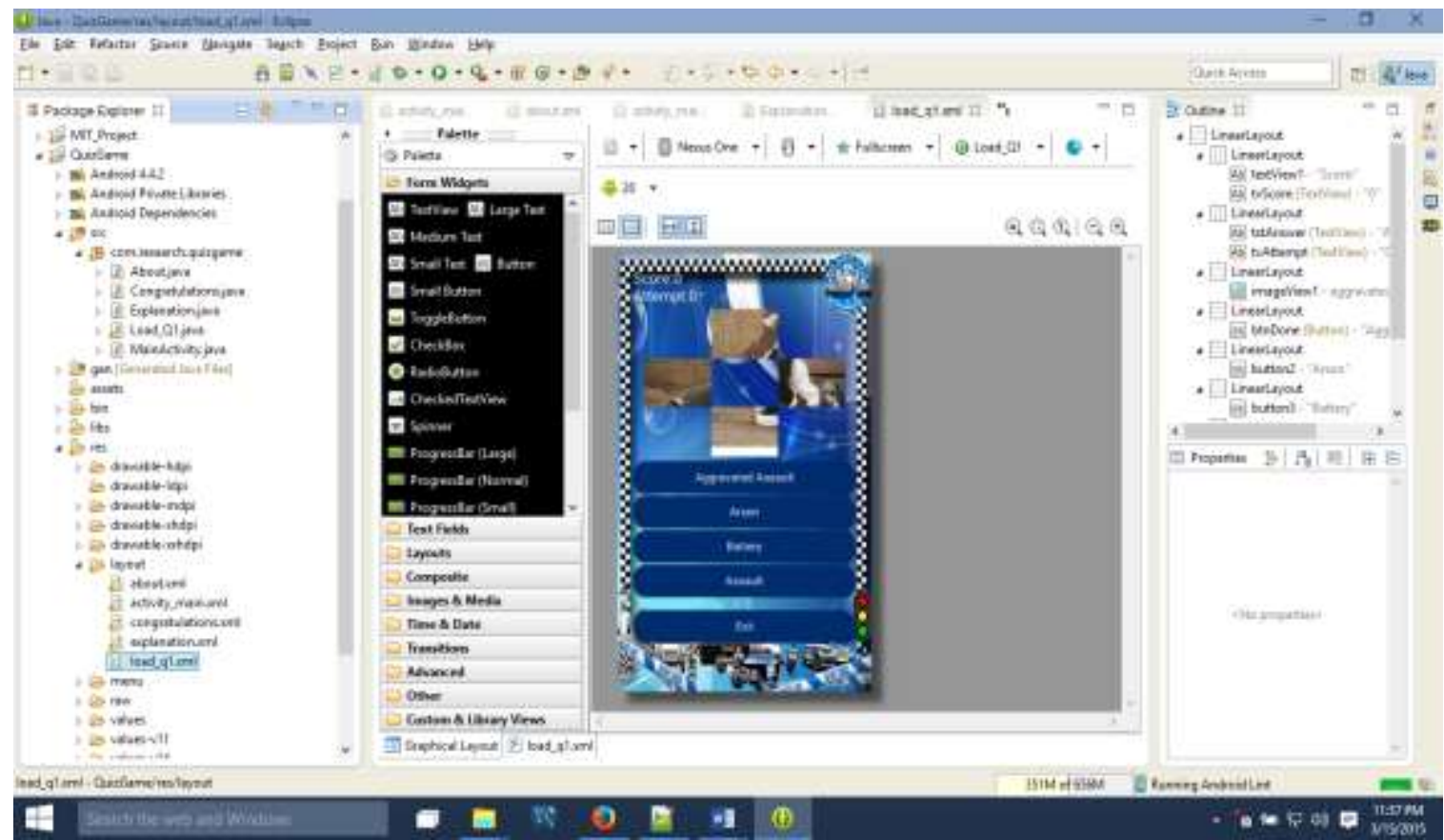

Figure 5. The image sample GUI of the question screen in Eclipse JUNO.

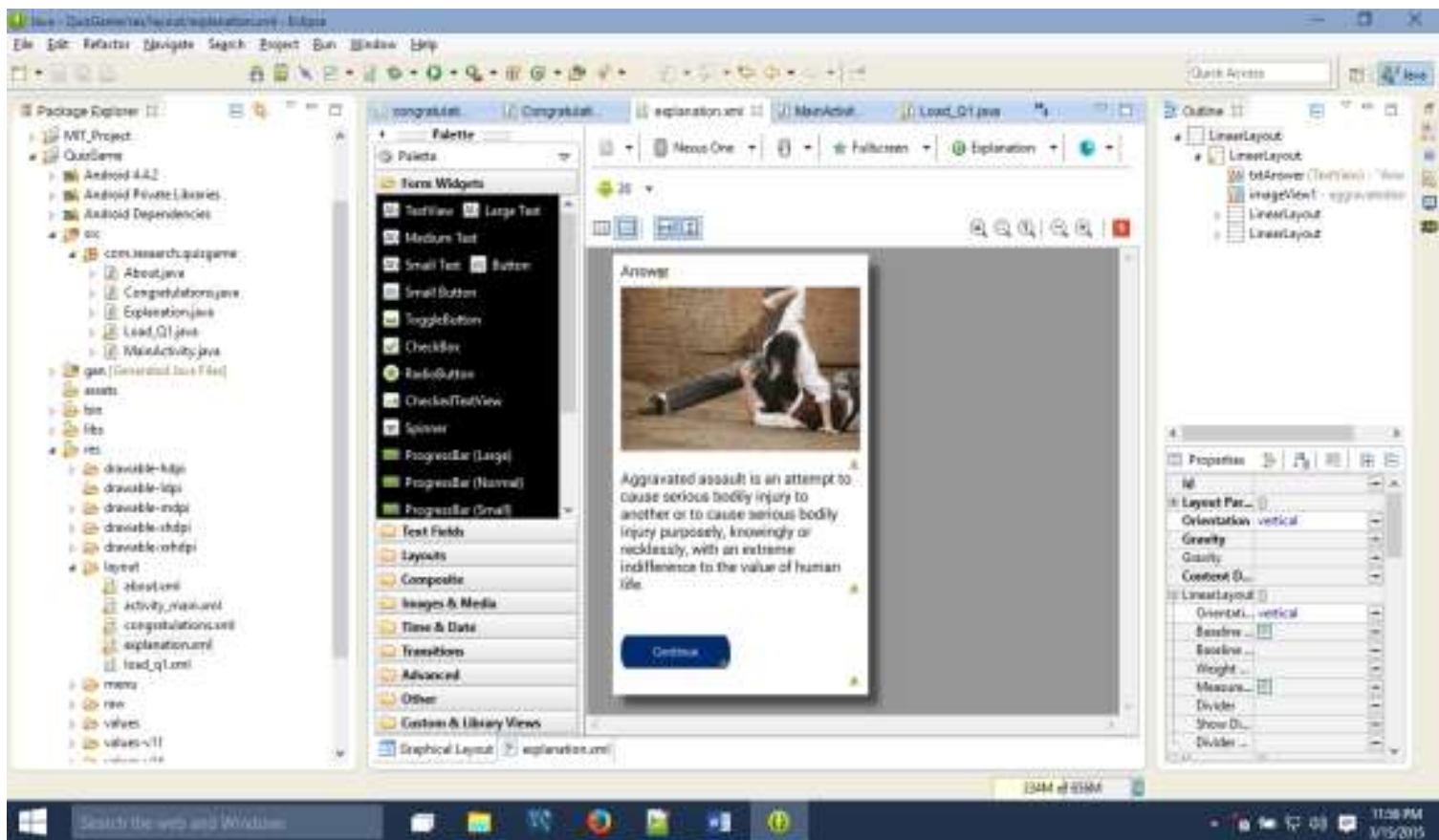

Figure 6. Image showing additional info for a correct answer. 


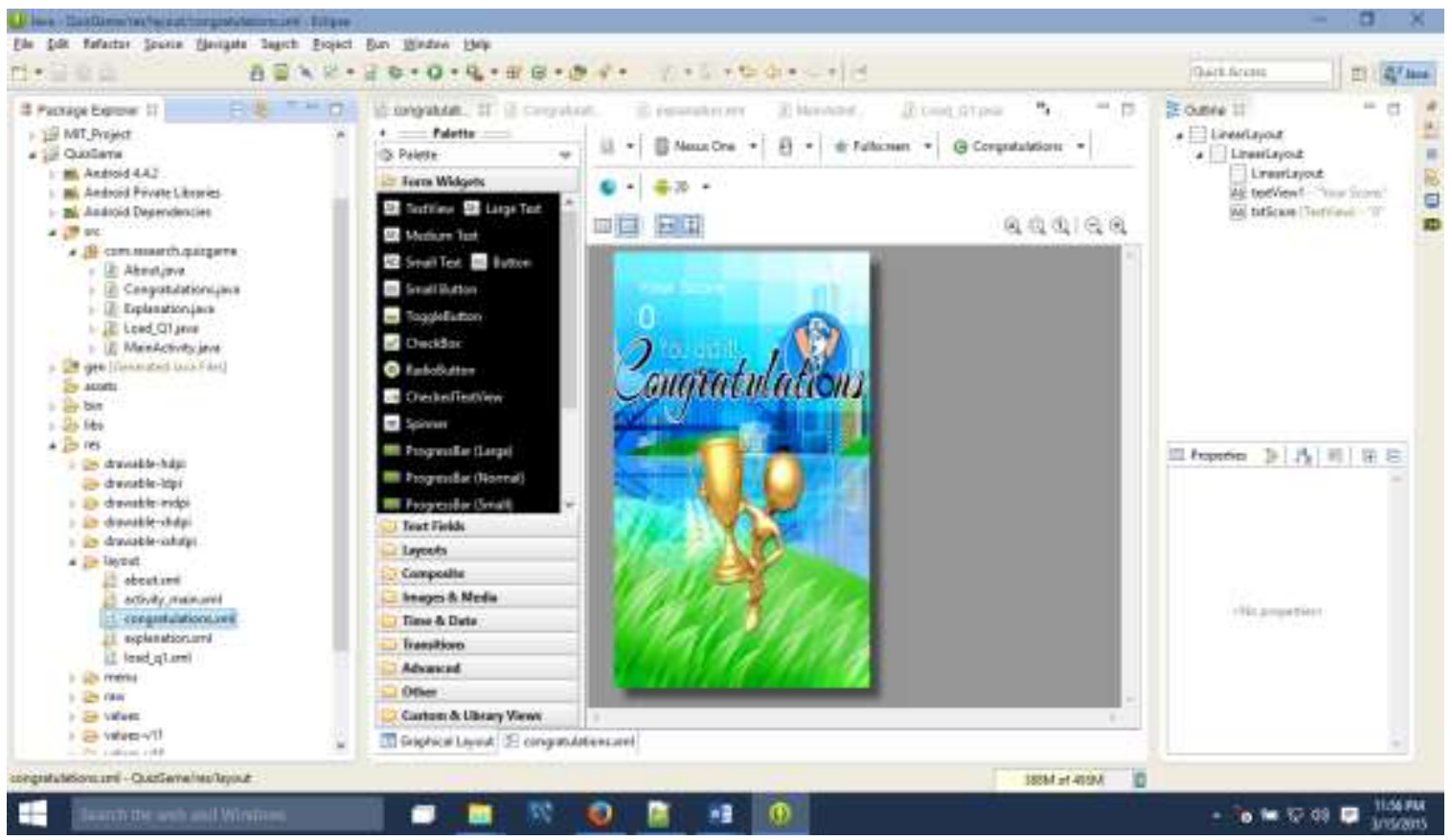

Figure 7. Image showing the GUI after the gamed was played completely

\section{Deployment}

In this phase, the researcher had installed the game on an Android-supported device to test if the game is functional. Deployment was done by compiling the game component into an app package. It was then deployed on a device via a universal serial cable or Bluetooth.

\section{Operation and Maintenance}

In this phase, the game is manipulated the way it should be. Testing of the game was also done during this phase. The final app was then tested on several android devices will to ensure their coding run successfully.

\section{Statistical Analysis}

The data were tabulated, computed, and analyzed based on the rating scale with the following interpretation

\begin{tabular}{|c|c|l|}
\hline 5 & 5.0 & $\begin{array}{l}\text { Excellent. The system is very much accessible, efficient and } \\
\text { accurate during the operation. The program did not experience } \\
\text { malfunctioning }\end{array}$ \\
\hline 4 & $4.0-4.9$ & $\begin{array}{l}\text { Very Good. The system is very accessible, efficient, and very } \\
\text { accurate during the operation. The program happened to experience } \\
\text { malfunctioning once. }\end{array}$ \\
\hline 3 & $3.0-3.9$ & $\begin{array}{l}\text { Good. The system is accessible, efficient, and accurate during the } \\
\text { operation. The program happened to experience malfunctioning. }\end{array}$ \\
\hline 2 & $2.0-2.9$ & $\begin{array}{l}\text { Fair. The program is sometimes accessible, efficient, and accurate } \\
\text { during the operation. The system happened to experience } \\
\text { malfunctioning }\end{array}$ \\
\hline 1 & $1.0-1.9$ & $\begin{array}{l}\text { Poor. The system is not accessible, efficient, and accurate during } \\
\text { the operation }\end{array}$ \\
\hline
\end{tabular}




\section{RESULTS AND DISCUSSION}

Criminology Android Educational Game was realized with the use of Eclipse JUNO, Photo Editing tools, and JAVA as the main programming language. The main purpose of the developed game is to help students boost their intellectual aspect in criminology. The developed game was based on the missing picture concept which enables the user of the game to guess and select the appropriate answer that would fit the missing pictures displayed on the screen. The game features used advanced GUI that could stimulate students' interest in the game. The game was expected to enhance learning while doing it in a more creative and interesting way.

After the game app coding was done, the app was deployed on an android tablet model CloudPad 701 TV having Android 4.2.2 version firmware. The Codified Project Management Framework was also used during the development of the project. Moreover, the app dry run was undergone to determine the lacking aspect of the game and to identify further the other things that should be added and integrated into the developed game. The image below shows the main menu of the system and its other components.

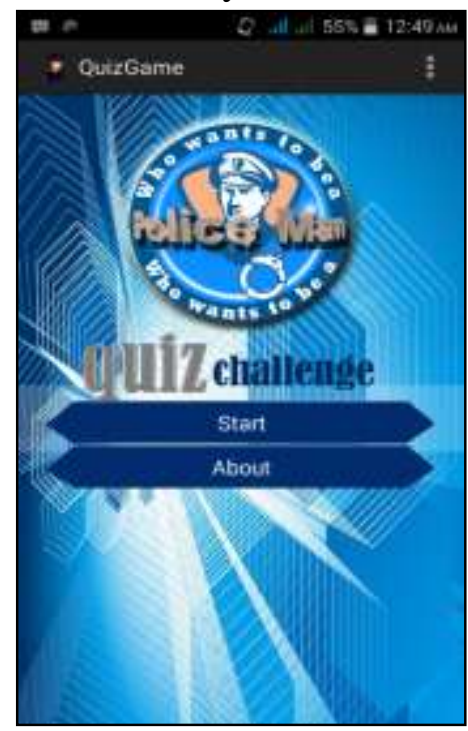

Figure 8. Main Screen of the Criminology Android Educational App

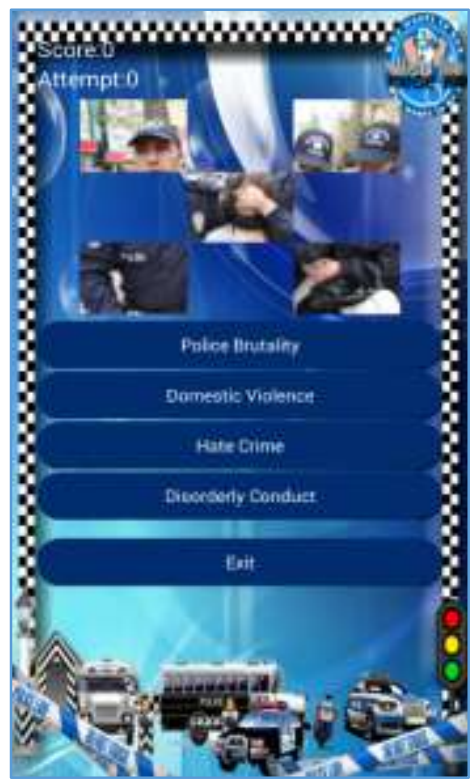

Figure 9. Showing the missing picture and the possible answer 


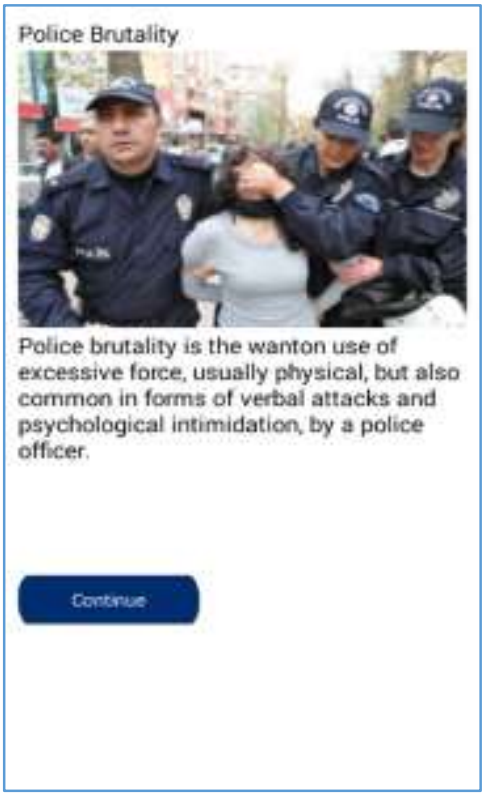

Figure 10. Supplemental Explanation for every App

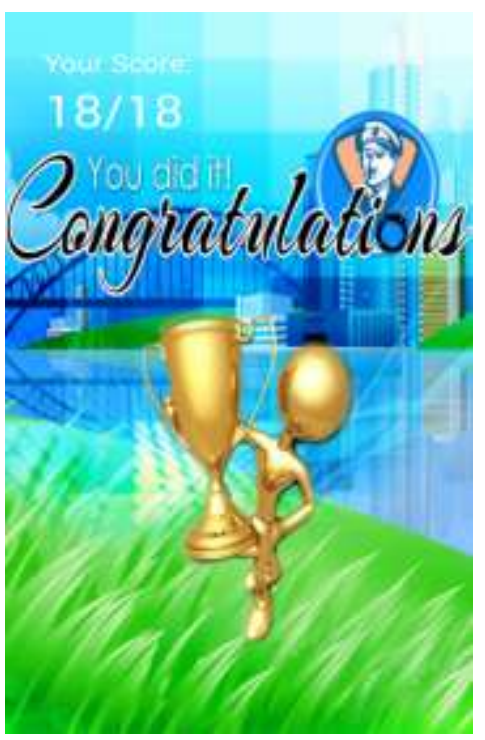

Figure 11. Confirmation screen when you a perfect score was got.

\section{RESULT AND DISSCUSSION}

Results were computed and analyzed based on the constructed questionnaire that were evaluated by ten (10) criminology students. The result based on the Interface of the system obtained an average mean 4.9, which was interpreted as "Very-good" which means that the Android App concept for criminology students is effective and excellent.

Table 1. Result of the System Evaluation

\begin{tabular}{|c|c|c|}
\hline \multicolumn{3}{|l|}{ Android App Interface, Functionality and Accuracy } \\
\hline Questions & Mean & Implementation \\
\hline 1. Graphical User-interface? & 5 & Excellent \\
\hline $\begin{array}{l}\text { 2. User-friendly (Easy to Understand and Manipulate by the } \\
\text { User?) }\end{array}$ & 4.7 & Very-good \\
\hline
\end{tabular}




\begin{tabular}{|c|c|c|}
\hline 3. The android app is able to response and interact in user's & 4.9 & Very-good \\
operation?? & 5 & Excellent \\
\hline 4. The android app able to show its exact images, answers and \\
results?
\end{tabular}

\section{CONCLUSION AND RECOMMEDATION}

Based on the result of the Interface of the system obtained, the Android App concept for criminology students is effective and excellent. It was further recommended that the developed app still be reviewed thoroughly in terms of its data content validity. It was also recommended that the system will be developed further for more additional features.

\section{REFERENCES}

Noemí, P. M., \& Máximo, S. H. (2014). Educational Games for Learning. Universal Journal of Educational Research, 2(3), 230-238. https://doi.org/10.13189/ujer.2014.020305

Cheung, S. Y., \& Ng, K. Y. (2021). Application of the Educational Game to Enhance Student Learning. Frontiers in Education, 6. https://doi.org/10.3389/feduc.2021.623793

Selvi, M., \& ÖZtürk ÇOşan, A. (2018). The Effect of Using Educational Games in Teaching Kingdoms of Living Things. Universal Journal of Educational Research, 6(9), 20192028. https://doi.org/10.13189/ujer.2018.060921

Areed, M. F., Amasha, M. A., Abougalala, R. A., Alkhalaf, S., \& Khairy, D. (2021). Developing gamification e-quizzes based on an android app: the impact of asynchronous form. Education and Information Technologies, 26(4), 4857-4878. https://doi.org/10.1007/s10639-021-10469-4

Inettutor.com. (2015, December 12). Android Based E-Learning Application for Criminology Students. https://www.inettutor.com/source-code/android-based-elearning-application-for-criminology-students/

Maire Byrne Evans. (2013, May 17). Crime Apps and Social Machines - Crowdsourcing Sensitive Data. http://www.slideshare.net/maireabyrne/crime-apps-and-social-machinescrowdsourcing-sensitive-data?qid=1c156825-b1d9-4801-

$81 \mathrm{bfec} 710 \mathrm{f} 12292 \mathrm{~d} \& \mathrm{v}=$ default $\& \mathrm{~b}=\&$ from_search $=5$

https://play.google.com/store/apps/details?id=com.appbookshop.criminology\&hl=en

http://apk.onl/Android/App/apps.dps.criminology

http://appcrawlr.com/app/related/1133728

http://study.com 